\title{
Crop evapotranspiration estimation using remote sensing and the existing network of meteorological stations in Cyprus
}

\author{
G. Papadavid $^{1,2}$, D. Hadjimitsis ${ }^{1}$, S. Michaelides $^{3}$, and A. Nisantzi ${ }^{1}$ \\ ${ }^{1}$ Department of Civil Engineering and Geomatics, Remote Sensing Laboratory, Cyprus University of Technology, \\ Lemesos, Cyprus \\ ${ }^{2}$ Cyprus Agricultural Research Institute, Nicosia, Cyprus \\ ${ }^{3}$ Meteorological Service, Nicosia, Cyprus
}

Received: 13 September 2010 - Revised: 27 January 2011 - Accepted: 10 March 2011 - Published: 9 May 2011

\begin{abstract}
Cyprus is frequently confronted with severe droughts and the need for accurate and systematic data on crop evapotranspiration (ETc) is essential for decision making, regarding water irrigation management and scheduling. The aim of this paper is to highlight how data from meteorological stations in Cyprus can be used for monitoring and determining the country's irrigation demands. This paper shows how daily ETc can be estimated using FAO PenmanMonteith method adapted to satellite data and auxiliary meteorological parameters. This method is widely used in many countries for estimating crop evapotranspiration using auxiliary meteorological data (maximum and minimum temperatures, relative humidity, wind speed) as inputs. Two case studies were selected in order to determine evapotranspiration using meteorological and low resolution satellite data (MODIS - TERRA) and to compare it with the results of the reference method (FAO-56) which estimates the reference evapotranspiration (ETo) by using only meteorological data. The first approach corresponds to the FAO PenmanMonteith method adapted for using both meteorological and remotely sensed data. Furthermore, main automatic meteorological stations in Cyprus were mapped using Geographical Information System (GIS). All the agricultural areas of the island were categorized according to the nearest meteorological station which is considered as "representative" of the area. Thiessen polygons methodology was used for this purpose. The intended goal was to illustrate what can happen to a crop, in terms of water requirements, if meteorological data are retrieved from other than the representative stations. The use of inaccurate data can result in low yields or excessive ir-
\end{abstract}

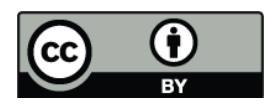

Correspondence to: G. Papadavid (papadavid@arinet.ari.gov.cy) rigation which both lead to profit reduction. The results have shown that if inappropriate meteorological data are utilized, then deviations from correct ETc might be obtained, leading to water losses or crop water stress.

\section{Introduction}

Evapotranspiration is referred to as the combination of two different processes: on the one hand, water is lost from the soil and plant surfaces by evaporation; on the other hand, water is lost from the crop by transpiration (FAO, 1998). The actual estimation and calculation of evapotranspiration is of vital importance in water resource management and determination of irrigation demand (Boegh and Soegaard, 2004; Hoedjes et al., 2008). Reference evapotranspiration (ETo) can be calculated by using meteorological data and typical reference crops with specialized instruments, such as lysimeters (Courault et al., 2005; Hadjimitsis et al., 2008).

Estimation of evapotranspiration combining conventional meteorological ground measurements with remotely-sensed data has been also widely investigated (Allen, 1996, 2000). Several methods using various satellite data have been developed, as shown by Gieske and Wouter (2005) using low resolution NOAA images, Papadavid et al. (2009), Hafeez et al. (2002), Sobrino et al. (2004), Qin and Karnieli (2001) using medium resolution Landsat/ETM+ satellite images and French et al. (2001) using ASTER satellite images. Despite the variety of methods for determining the evapotranspiration for irrigation purposes, local authorities or governmental offices require a simplified and quick approach. Indeed, the use of meteorological data acquired from nearby meteorological stations can be used for such purposes, in

Published by Copernicus Publications on behalf of the European Geosciences Union. 
combination with other existing tools, such as satellite remote sensing. Currently, several researchers recommend a breadth of mathematical equations and modelling (Menenti et al., 1989; D’Urso and Menenti, 1995; Bastiaanssen et al., 1998; Bastiaanssen and Ali, 2003). The methods of estimating ETc are generally classified as: (a) energy balance methods, (b) aerodynamic or mass transfer methods, (c) empirical or semi-empirical methods, (d) water depletion methods and (e) numerical or modeling methods (Eliadis et al., 1995; Metochis, 1997). The analysis of the performance of these models revealed the need for formulating a standard method for the computation of ETo (Tsouni and Koutsogiannis, 2003; Hoedjes et al., 2008). The FAO-56 method, which was derived from the Penman-Monteith equation, has recently been recommended as the sole standard method (Telis and Koutsogiannis, 2007); this a method with strong likelihood of correctly predicting ETo in a wide range of locations and climates (D' Urso and Menenti, 1995; Aaron et al., 1996).

The paper has the following two objectives:

1. To highlight how meteorological data can reduce the accuracy in estimating ETc, if they are taken from stations that are located beyond a critical distance; the intended purpose is to show that other than the area's meteorological data could cause problems in irrigation scheduling which could lead to crop health related problems.

2. To propose a methodology for choosing the nearest meteorological station for meteorological data acquisition regarding hydrological purpose studies and more specifically for estimating evapotranspiration.

\section{Data and methodology}

In the first part of this study, the FAO Penman-Monteith method adapted to satellite data is used to estimate potatoes' ETc and then compare it to FAO-56. In the second part, the accuracy of the former method is evaluated by incorporating meteorological data from other meteorological stations established on the island. For this purpose, Cyprus is divided into five geographical areas in accordance with the distance from the main five meteorological stations of the island. Two case studies are selected in order to check the impact of "noncorrect" (i.e. less representative) meteorological data on ETc.

\subsection{Case studies}

Mandria and Kokkinochoria, the main irrigated areas of the island of Cyprus, have been used as pilot study areas (Fig. 1). For these areas crop evapotranspiration was determined using both meteorological and satellite data. The selected areas are traditionally agricultural with a diversity of annual cultivations. The areas are flat and at almost sea level, while the surface can be considered as homogenous.

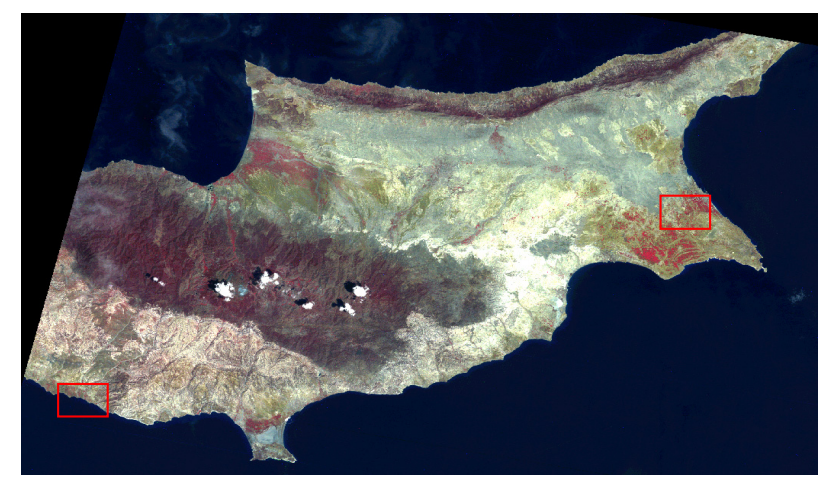

Fig. 1. Landsat TM image of Cyprus: Mandria (left) and Kokkinochoria (right) area.

\subsection{Resources}

In order to estimate evapotranspiration using FAO PenmanMonteith method adapted to satellite data, auxiliary meteorological data from Paphos's airport automatic meteorological station were used. The data include air temperature, atmospheric pressure, wind speed, among other meteorological parameters. Moreover, 14 low resolution MODIS Terra images were used, dating from 25 January 2009 to 9 May 2009. These data were used to retrieve the surface albedo (MODIS albedo maps) from surface reflectance bands of MODIS. Despite the fact that these images have very low spatial resolution, MODIS images pass over Cyprus every day and can assist in the estimation of evapotranspiration on a regular basis.

For the second objective of the paper, three Landsat TM and ETM+ images have been used. ETc was calculated for Mandria and Kokkinochoria area using data from the "proper" (implying the closest to the area) and "non-proper" meteorological stations, in order to test the reliability of using data from any meteorological station.

\subsection{Methodology}

FAO method adapted to satellite data was used to estimate ETc. The use of both satellite and meteorological data are required to employ the method. The specific equation which is used to estimate ETc, under certain conditions (see below), is based on the direct application of the Penman-Monteith equation with canopy parameters estimated from satellite imagery. Air temperature, atmospheric pressure, wind speed and other data were collected from meteorological stations located next to areas of interest. Equation (1) shows how ETc can be estimated using the mentioned above method.

$\mathrm{ETc}=$
$\frac{86400}{\lambda}\left[\frac{s\left(1-0.4 e^{-0.5 \mathrm{LAI}}\right)(1-a)\left(\mathrm{K} \downarrow+\mathrm{L}^{*}\right)+c_{p} p_{a}\left(e_{s}-e_{a}\right) U / 124}{s+\gamma(1+U / 0.62 \mathrm{LAI})}\right]$ 


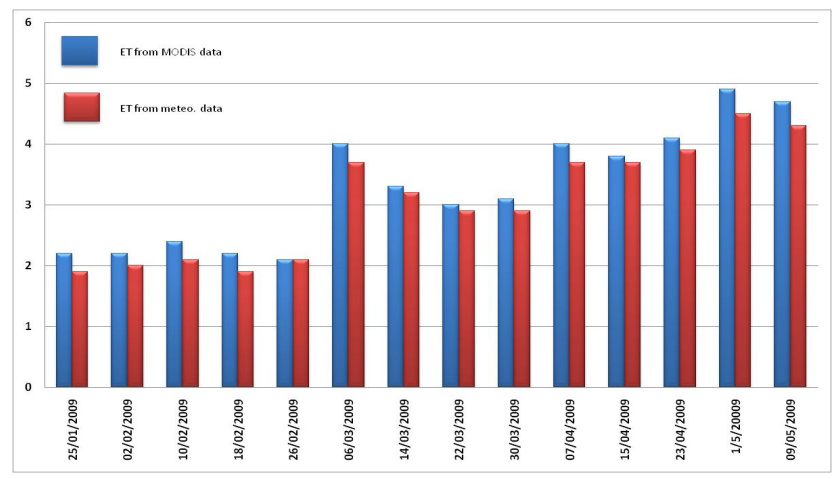

Fig. 2. Crop evapotranspiration using meteorological and satellite data.

where $K \downarrow$ is the incoming solar radiation and $U$ the wind speed; the other variables, namely $L^{*}$ (net longwave radiation), $c p$ (air specific heat), $\rho a$ (air density), (es-ea) (vapour pressure deficit), $\lambda$ (latent heat of vaporisation of water) $\alpha$ is the albedo derived directly from MODIS maps, $s$ is the slope vapour pressure curve and $\gamma$ (thermodynamic psychrometric constant) are calculated from air temperature and humidity at $2.0 \mathrm{~m}$ reference height. This equation is valid under conditions of high solar irradiance (typical summer condition in Mediterranean climate) and for LAI $>0.5$ (LAI is the Leaf Area Index), which is the case for Cyprus' annual crops. For the calculation of LAI, an empirical exponential equation for Cyprus' conditions and especially for annual crops was used:

$\mathrm{LAI}=0.004 e^{11.8 \times \mathrm{WDVI}}$

where WDVI is the Weighted Difference Vegetation Index (Clevers, 1988). The equation is proposed by Papadavid and Hadjimitsis (2009), after correlating LAI to many vegetation indices and choosing the one with the strongest determination coefficient $\left(r^{2}\right)$. Satellite data, such as LAI and albedo maps, have been derived from satellite imagery from Landsat, using simplified methods (D'Urso and Menenti, 1995). For deriving albedo, Liang's equation was used (Liang, 2000).

After inferring the necessary inputs for the FAO model adapted to satellite data, the model is applied for retrieving ETc values from the satellite data. Cetris paribus, but changing the albedo value and the value of WDVI, ETc values for each date were estimated and compared.

Thiessen polygons can be used to describe the area of influence of a point against other points. If one takes a set of points and connects each point to its nearest neighbour, then a triangulated irregular network is obtained (Collins and Bolstad, 1996); closed polygons are created by generating perpendicular bisectors for each triangle edge. The locations at which of the bisectors intersect determine the locations of the Thiessen polygon vertices. The area contained in each polygon is closer to the point on which the polygon is based

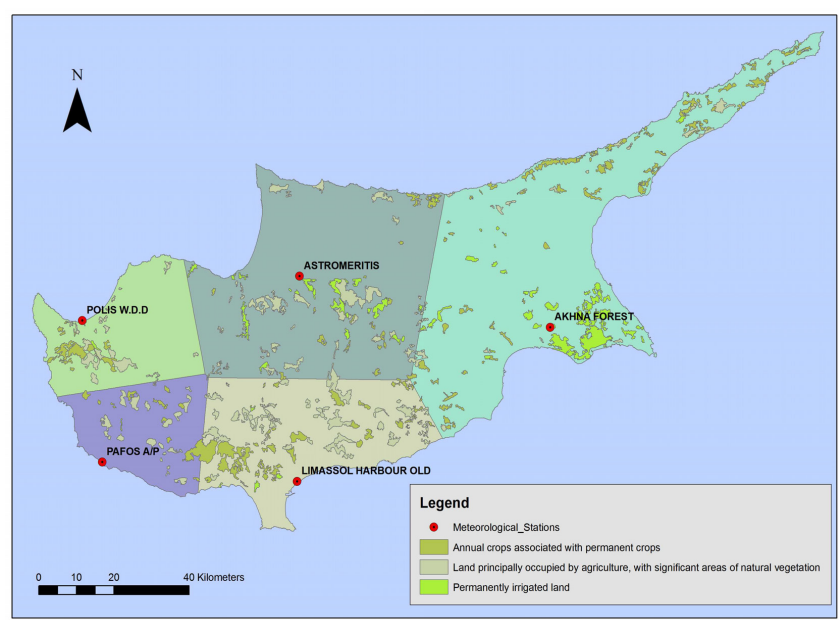

Fig. 3. Cyprus division according to Thiessen methodology.

than to any other point in the dataset (Burrough, 1986). For the purposes of this study, Thiessen methodology was employed to divide Cyprus geographically according to the distance from the five main meteorological stations situated in the territory of the island.

Finally, after dividing Cyprus in five territories, two pilot study areas were considered. In both areas, the analysis used data from all the meteorological stations situated all over the island of Cyprus and assesses the accuracy of the method when meteorological data from distance stations are included.

\section{Results}

\subsection{ETc comparison}

FAO Penman-Monteith method for estimating crop evapotranspiration (ETc), has been applied using MODIS satellite data and meteorological records. The final results have been tabulated and shown in Fig. 2. These results were compared to the FAO-56 method using only meteorological data and using a single crop coefficient for potatoes $(\mathrm{Kc})$. It is obvious that ETc sourcing from MODIS and meteorological data is always less than that of the FAO. The reason for this could be the low resolution of MODIS pixel. The difference is insignificant but to increase accuracy of the methodology the FAO-56 (using only meteorological data and crop coefficient) method will be used when estimating ETc, for the rest of the study.

\subsection{Thiessen polygons}

In order to determine the suitability of the meteorological stations for estimating ETc, a spatial analysis called Thiessen polygons was applied (Burrough and McDonnell, 1998). 
Table 1. ETo (mm/day) using FAO-56 method.

\begin{tabular}{lccccc}
\hline Station & \multicolumn{5}{c}{ Date } \\
& $20 / 11 / 03$ & $05 / 8 / 04$ & $13 / 8 / 08$ & $23 / 7 / 09$ & $25 / 9 / 09$ \\
\hline Polis & 2.50 & 7.50 & 7.50 & 7.40 & 4.50 \\
Paphos airport & 2.60 & 5.80 & 5.50 & 6.70 & 4.60 \\
Limassol harbour (old) & 2.10 & 6.10 & 5.90 & 6.40 & 4.90 \\
Astromeritis & 1.60 & 6.30 & 6.60 & 8.10 & 5.20 \\
Achna forest station & 2.30 & 6.00 & 5.90 & 8.10 & 5.30 \\
\hline
\end{tabular}

Table 2. ETc using FAO method, remote sensing and meteorological data at Kokkinochoria irrigated area. The underlined results correspond to the meteorological station that is closest to the irrigated area of interest.

\begin{tabular}{|c|c|c|c|}
\hline \multirow{2}{*}{ Station } & \multicolumn{3}{|c|}{ Date } \\
\hline & $20 / 11 / 2003$ & $13 / 08 / 2008$ & $25 / 09 / 2009$ \\
\hline Polis & 2.90 & 8.00 & 5.10 \\
\hline Paphos airport & 3.00 & 5.90 & 5.10 \\
\hline Limassol harbour (old) & 2.50 & 6.40 & 5.80 \\
\hline Astromeritis & 2.10 & 7.20 & 6.00 \\
\hline Achna forest station & 2.70 & 6.30 & 6.00 \\
\hline
\end{tabular}

More specifically, five main automatic meteorological stations of Cyprus were mapped and then Thiessen polygons were created in order to identify which areas were closer to each station (see Fig. 3 with mapped agricultural areas of Cyprus)

ETo for five different dates, according to FAO-56 method, using only meteorological stations' data was calculated as shown in Table 1. Having known the ETo and by multiplying it with the crop coefficient, each farmer can calculate the daily needs of a cultivation (actual evapotranspiration). As can be seen from Table 1 the selection of the nearest meteorological station can be crucial to determine accurate results. In cases where meteorological data from the nearest meteorological station are unavailable, an approximation can be made using other meteorological stations, but an average error of $\pm 0.45 \mathrm{~mm} \mathrm{day}^{-1}$ may expected in such cases. The average error is estimated as the average value of all the cases when using other meteorological data than from the 'proper' meteorological station.

The ETc was calculated using medium resolution satellite images (Landsat images). The final results are shown in Tables 2 and 3 (Kokkinochoria and Mandria irrigated areas, respectively). The underlined results are considered to be the most accurate since the meteorological station is situated very near the irrigated area of interest. The results refer to ETc in $\mathrm{mm} /$ day for potatoes.

From the results shown in Tables 2 and 3, one can estimate the "greater" or 'smaller' amount of water consumption over one hectare of agricultural area by using data from other me-
Table 3. Same as Table 2, but for Mandria irrigated area.

\begin{tabular}{lccc}
\hline Station & \multicolumn{3}{c}{ Date } \\
& $20 / 11 / 2003$ & $13 / 08 / 2008$ & $25 / 09 / 2009$ \\
\hline Polis & 3.10 & 8.00 & 5.00 \\
Paphos airport & 3.20 & 6.10 & 5.10 \\
Limassol harbour (old) & 2.70 & 6.40 & 5.70 \\
Astromeritis & 2.30 & 7.20 & 5.90 \\
Achna forest station & 2.90 & 6.30 & 6.00 \\
\hline
\end{tabular}

Table 4. Water losses (tonnes per month) for 1 hectare (Kokkinochoria area)

\begin{tabular}{lrrr}
\hline Station & \multicolumn{3}{c}{ Date } \\
& $20 / 11 / 2003$ & $13 / 8 / 2008$ & $25 / 9 / 2009$ \\
\hline Polis & 60.0 & 510.0 & -270.0 \\
Paphos airport & 90.0 & -120.0 & -270.0 \\
Limassol harbour (old) & -60.0 & 30.0 & -60.0 \\
Astromeritis & -180.0 & 270.0 & 0.0 \\
\hline
\end{tabular}

teorological stations situated away from the area of interest. Irrigation water losses or deficit for a month are calculated as shown in Tables 4 and 5. The name of the meteorological stations is stated in the first column, while the deficit or excess of irrigated water is indicated in the second, third and fourth columns.

As it is shown, a sophisticated irrigation schedule can be performed using meteorological and satellite images data for estimating evapotranspiration. This fact will contribute to the reduction of water losses in irrigation and will contribute, indirectly, to the increase of the water reservoirs in Cyprus.

\section{Discussion and conclusions}

This paper aims at highlighting the importance of using both meteorological and satellite image data for estimating ETc in Cyprus. Indeed, in the procedure of estimating ETc, the results have shown that there is a need for choosing the closest meteorological station to retrieve data from. The use of satellite images have assisted in dividing Cyprus in polygons according to its main meteorological stations. Based on this method (Thiessen polygons) ETc was estimated for five agricultural sites. In parallel, ETc was estimated by using data from other meteorological stations situated in Cyprus, but not in the respective area of interest. It was found that if the meteorological data does not refer to the appropriate meteorological station, significant deviations on ETc may take place. Hence, it is important to have the appropriate meteorological data of the area of interest in order to increase the accuracy of the results, regarding ETc estimation. 
Table 5. Water losses (tonnes per month) for 1 hectare (Mandria area).

\begin{tabular}{lrrr}
\hline Station & \multicolumn{3}{c}{ Date } \\
& $20 / 11 / 2003$ & $13 / 8 / 2008$ & $25 / 9 / 2009$ \\
\hline Polis & 60.0 & 510.0 & -270.0 \\
Paphos airport & 90.0 & -120.0 & -270.0 \\
Limassol harbour (old) & -60.0 & 30.0 & -60.0 \\
Astromeritis & -180.0 & 270.0 & 0.0 \\
\hline
\end{tabular}

Determination of evapotranspiration using both meteorological and satellite remote sensing data is planned for further future research. Furthermore, other methods for estimating irrigation demand will be evaluated in the near future.

Acknowledgements. The authors would like to express their appreciation to Cyprus Research Promotion Foundation (www.research.org.cy), the European Union and the Cyprus University of Technology for their funding support. Thanks are given to the Remote Sensing Laboratory of the Department of Civil Engineering \& Geomatics at the Cyprus University of Technology (www.cut.ac.cy).

Edited by: S. Athanasatos

Reviewed by: two anonymous referees

\section{References}

Aaron, M., Beutler, B.S., and Keller, A.: Implementation of FAO56 Penman-Monteith evapotranspiration in a large scale irrigation scheduling, Water and Environmental Resources Congress, Alaska, 1996.

Allen, R. G.: Assessing integrity of weather data for use in reference evapotranspiration estimation, Irrig. Drain., ASCE 122, 97-106, 1996.

Allen, R. G., Pereira, L. S., Raes, D., and Smith, M.: Crop evapotranspiration, Irrig. Drain. 56, 2000.

Bastiaanssen, W. G. M., Menenti, M., Feddes, R. A., and Holtslag, A. A. M.: A remote sensing surface energy balance algorithm for land (SEBAL), Part 1: formulation, J. Hydrol., 212-213, 198212, 1998.

Bastiaanssen, W. G. M. and Ali, S.: A new crop yield forecasting model based on satellite measurements applied across the Indus Basin, Pakistan, Agriculture, Ecosystems and Environment, 94, 321-340, 2003.

Boegh, E. and Soegaard, H.: Remote Sensing based estimation of Evapotranspiration rates, Int. J. Remote Sens., 25, 2535-2551, 2004.

Burrough, P. A.: Principles of Geographical Information Systems for Land Resource Assessment, New York, Oxford University Press, 1986.

Burrough, P. A. and McDonnell, R. A.: Principles of Geographical Information Systems, New York, Oxford University Press, 1998.
Clevers, J. G. P. W.: The derivation of a simplified reflectance model for the estimation of leaf area index, Remote Sens. Environ., 35, 53-70, 1988.

Collins, F. C. and Bolstad, P. V.: A comparison of spatial interpolation techniques in temperature estimation, in: Proceedings of the Third International Conference/Workshop on Integrating GIS and Environmental Modeling, Santa Fe, New Mexico, 2125 January, 1996.

Courault, D., Seguin, B., and Olioso, A.: Review on estimation of Evapotranspiration from remote sensing data: from empirical to modeling approaches, Irrig. Drain., 19, 223-249, 2005.

D’Urso, G. and Menenti, M.: Mapping crop coefficients in irrigated areas from Landsat TM images; Proceed, Opt. Eng., 2585, 4147, 1995.

Eliadis, G., Metochis, C., and Papachristodoulou, S.: Technoeconomic analysis of irrigation in Cyprus, Cyprus Agricultural Research Institute Series, Ministry of Agriculture, Natural Resources and Environment Publications, Cyprus, Nicosia, 1995.

FAO: Crop evapotranspiration, Guidelines for computing crop water requirements, FAO Irrigation and Drainage Paper No. 56, Food and Agriculture Organization of the United Nations, 1998.

French, A. N., Schmugge, T. J., and Kustas, W. P.: Estimating evapotranspiration with ASTER thermal infrared imagery, Journal of Geoscience and Remote Sensing Symposium, 2, 718-720, 2001.

French, A. N., Hunsaker, D., Thorp, K., and Clarke, T.: Evapotranspiration over a camelina crop at Maricopa, Arizona, INDCRO 5170, 2008.

Gieske, A. and Wouter M.: High density NOAA time series of ET in the Gediz Basin, Turkey, Journal of Irrigation and Drainage Systems, 19, 285-299, 2005.

Hadjimitsis, D. G., Papadavid, G., and Kounoudes, A.: Integrated method for monitoring irrigation demand in agricultural fields in Cyprus using satellite remote sensing and wireless sensor network, 4th International Conference on Information \& Communication Technologies in Bio \& Earth Sciences, Athens, Greece, 2008.

Hafeez, M. M., Chemin, Y., Van De Giesen, N., Bouman, B. A. M.: Field Evapotranspiration Estimation in Central Luzon, Philippines, Using Different Sensors: Landsat 7 ETM+, Terra Modis and Aster, In Proc. Symposium on Geospatial Theory, Processing and Applications, Ottawa, 2002.

Hoedjes, J. C. B., Chehbouni, A., Jacob, F., Ezzahar, J., and Boulet, G.: Deriving daily Evapotranspiration from remotely sensed evaporative fraction over olive orchard in Morocco, J. Hydrol., 53-64, 2008.

Liang S.: Narrowband to broadband conversions of land surface albedo: I Algorithms, Remote Sens. Environ., 78, 213-238, 2000.

Menenti, M., Visser, T. N. M., Morabito, J. A., and Drovandi, A.: Appraisal of irrigation performance with satellite data and georeferenced information, Irrigation Theory and Practice, 785-801, 1989.

Metochis, C.: Assessment of irrigation water needs of main crops of Cyprus., Cyprus Agricultural Research Institute Series, Ministry of Agriculture, Natural Resources and Environment, Nicosia, 1997.

Papadavid, G., Agapiou, A., Hadjimitsis, D., Themistocleous, K.: Estimating Evapotranspiration of spring potatoes in Paphos, Cyprus using remote sensing, spectroradiometric and meteoro- 
logical data, Remote Sensing and Photogrammetry Society Annual Conference 2009, "New Dimensions in Earth Observation", Leicester, 8-11 September 2009, 2009.

Qin, Z. and Karnieli, A.: A mono-window algorithm for retrieving land surface temperature from Landsat TM data and its application to the Israel-Egypt border region, Int. J. Remote Sens., 22, 3719-3746, 2001.
Sobrino, J. A., Jimenez-Munoz, J. C., and Paolini, L.: Land surface temperature retrieval from LANDSAT TM 5, J. Remote Sens. Environ., 90, 434-440, 2004.

Telis, A. and Koutsogiannis, D.: Estimation of Evapotranspiration in Greece, PhD Thesis, Univ. of Athens, 2007.

Tsouni, A. and Koutsogiannis, D.: The contribution of remote sensing techniques to the estimation of Evapotranspiration: the case of Greece, PhD Thesis, Univ. of Athens, 2003. 